\title{
Robotic-assisted laparoscopic prostatectomy for a patient with clinically localized prostate cancer
}

\author{
Dominic Wang, Jamie Riggs
}

\section{CASE PRESENTATION}

A 56-year-old Hispanic male presents to the urology clinic upon referral from his family physician. Routine prostate screening and repeat prostate specific antigen (PSA) levels are positive for elevated PSA ( $8.4 \mathrm{ng} / \mathrm{mL})$. Two years prior, the patient's PSA levels were $1.2 \mathrm{ng} / \mathrm{mL}$. On digital rectal exam (DRE), the prostate is noted as hard, with a palpable nodule. There is no detectable extracapsular extension or seminal vesicle involvement on examination. $\mathrm{He}$ is otherwise healthy. The patient's uncle was diagnosed with metastatic prostate cancer in his 60s. After consultation with his family doctor, the patient comes to the urology clinic to discuss surgical management options.

\section{RECOMMENDATIONS FOR PROSTATE CANCER SCREENING}

PSA is a glycoprotein produced by prostate epithelial cells. ${ }^{1}$ PSA levels are elevated when its production is increased and the tissue between the prostate and the capillary is disrupted, as occurs in prostate cancer. ${ }^{1}$ The Canadian Urological Association (CUA) 2017 guidelines recommend routine PSA screening for men beginning at the age of 45 years with a family history of prostate cancer in a first- or second-degree relative, and beginning at 50 years for all other men. ${ }^{2}$ Men with PSA $>3 \mathrm{ng} / \mathrm{mL}$ should undertake more frequent testing, and be considered for adjunctive testing such as PSA kinetics, PSA density, percent free PSA, and biomarker panels to better assess the risk of developing prostate cancer. ${ }^{2}$ Positive PSA test results should be repeated, as a Canadian study has demonstrated that approximately $25 \%$ of cases resolve to low levels after repeat testing. ${ }^{3}$

Prostate cancer risk can be calculated using online tools, including the Prostate Cancer Prevention Trial Risk Calculator (PCPT-RC) and the European Randomized Study of Screening for Prostate Cancer Risk Calculator (ERSPC-RC).,5 PCPT-RC utilizes age, PSA level, ethnicity, family history, DRE results, and prior biopsy results. ERSPC-RC uses prostate volume and transrectal ultrasound findings in addition to variables used by PCPT-RC., ${ }^{4,5}$ PCPT-RC estimates the likelihood of low risk and high risk prostate cancerdefined as a biopsy with a Gleason score of $<7$ or $\geq 7$ respectivelywhile ERSPC-RC estimates the risk of any clinically significant risk prostate cancers. ${ }^{4,5}$ These calculators are easily accessible tools which estimate the risk of clinically significant prostate cancer, but they are only moderately accurate. ${ }^{2}$ The complete CUA guidelines are summarized in Figure $1 .^{2}$

\section{INITIAL PATIENT ASSESSMENT \& BIOPSY}

Given the clinical information available in the case presentation above, PCPT-RC is used to estimate the patient's prostate cancer risk. The patient has a $67 \%$ chance of a negative biopsy, a $24 \%$ chance of low-grade cancer, and a $9 \%$ chance of high-grade cancer.

The risks of a biopsy are discussed. The most common complication is infection. Studies have reported hospitalization rates due to infection ranging from 1 to $3 \%{ }^{6}$ Other complications include hemorrhage, urinary obstruction, and rarely tumour seeding. ${ }^{7-9}$ The patient elects to proceed with the biopsy using transrectal ultrasound-guided biopsy with prophylactic antibiotics.

The biopsy is positive for localized prostatic adenocarcinoma, with a Gleason score of $3+4=7$.

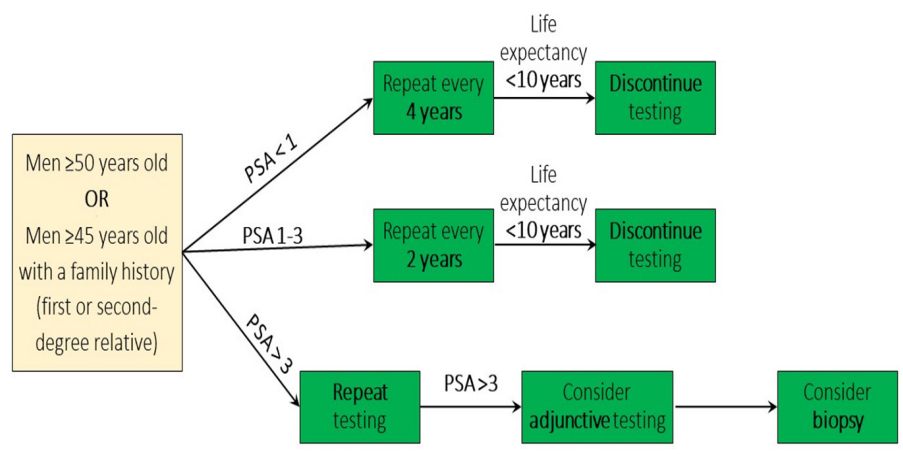

Figure 1. Prostate cancer screening using PSA. Adopted from the CUA 2017 guidelines. $^{2}$

\section{TREATMENT OPTIONS: RADIOTHERAPY VERSUS SURGERY}

Treatment varies depending on the risk of metastasis, as defined by the Gleason score. A Gleason score is reported in order of the most commonly found grades of the tumour found in the biopsy, with the total score stratifying the risk of a patient with clinically localized prostate cancer and PSA $<10$ for metastatic cancer as either: low- $(\leq 6)$, intermediate- $(7)$, or high-risk $(\geq 8) .{ }^{10}$

Radiotherapy or surgery are the standard treatments for intermediate-risk patients with a greater than 10-year life expectancy. ${ }^{11}$ Radiotherapy is given by either external beam alone or in combination with brachytherapy. Surgical options include radical prostatectomy $(\mathrm{RP})$, which involves complete removal of the prostate gland. Concurrent pelvic lymph node dissection is also recommended. ${ }^{11-13}$

There are several advantages of surgery in this patient whose life expectancy likely exceeds an additional 20 years, including better pathological staging, lymph node assessment, and the option of salvage radiotherapy if the cancer recurs.

\section{ROBOT-ASSISTED LAPAROSCOPIC PROSTATECTOMY}

Currently, all robotic surgical procedures involve the da Vinci Surgical System, pictured in Figure $2 .{ }^{14}$ This system of 4 multi-joint arms ( 1 controlling an endoscope, 1 for retraction, and 2 controlling 
other conventional laparoscopic instruments) is operated with a remote-operated console. ${ }^{14}$ New features continue to be released, with the latest model adding dual console capability to enable collaborative procedures. ${ }^{14}$ The console provides several advantages over traditional surgery, including enhanced manipulative dexterity of the surgical instruments, as well as the ability to filter hand tremors. ${ }^{14}$ Given its relatively recent release (the first model was introduced in 1999), there are many limitations for use of the da Vinci system in clinical practice. These include its limited compatibility with surgical instruments, as well as the cost and size of the machine..$^{14,15}$ In Canada, the price of a machine is $\$ 2.8$ million, with annual maintenance costs of $\$ 180000$ and an additional $\$ 3500$ for each operation. ${ }^{16}$ Robotic-assisted surgeries have been gaining in popularity, particularly among patients, with 85000 roboticassisted procedures performed in 2007 and 205000 in 2009. 14,15

Outcomes for robotic-assisted laparoscopic prostatectomy (RALP) do not differ significantly from non-robotically assisted prostatectomy. A meta-analysis comparing RALP with open retropubic RP (ORP) and laparoscopic RP (LRP) demonstrated similar hospital length of stay, blood loss and transfusion rates between RALP and LRP. ${ }^{17}$ However, there is a trend toward consistently better outcomes with RALP, varying based on the surgeon's experience. ${ }^{18}$ Additionally, perioperative and intraoperative complication rates were generally lower with RALP. $^{17}$ Other meta-analyses have also demonstrated a lower prevalence of 12-month urinary incontinence and impotence after RALP compared to ORP and LRP. ${ }^{19,20}$

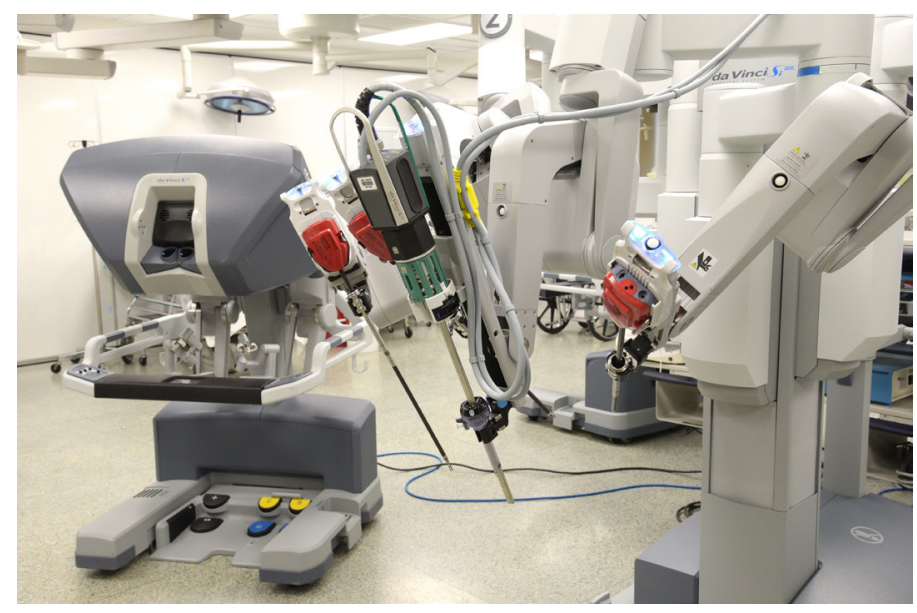

Figure 2. Example of a da Vinci Surgical System.

\section{ADDITIONAL CONSIDERATIONS OF ROBOTIC-ASSISTED SURGERIES}

Public perception of the addition of robots to surgical procedures is largely positive. Multiple news stories praise the perceived enhanced accuracy of robotic surgery and claim it would be a mistake for Canada to adopt these technologies at a slower rate. $^{21,22}$ Of 4100 da Vinci systems installed worldwide, 2703 have been in the United States, and only 31 currently in Canada. ${ }^{21}$

Though RALP and other robotic surgeries are promising additions to healthcare, cost-effectiveness analyses demonstrate large incremental costs compared to current standard therapy (\$3860 per patient compared to open surgery, $\$ 4625$ per patient compared to LRP). ${ }^{23}$ It is likely that widespread integration of robotic-assisted surgeries will require additional modifications to current technologies to reduce cost and improve benefits and outcomes.

Recent work has raised concerns about the effect of roboticallyassisted procedures on surgical residents' operative training. As the surgeon is not present at the bedside, but instead sits at a console some distance away, learners have reduced opportunity to be directly involved in assisting or carrying out parts of the procedure. Instead, they spend more time observing, and are often ill-prepared to carry out the procedure when given the chance. ${ }^{24}$ A survey of surgical residents suggests that while a majority are training at institutions with access to robotic surgery and have themselves participated in robotic cases, only $18 \%$ reported experience with operating at the console. ${ }^{25}$ However, some learners may be given the chance to operate using a second console, which allows for close supervision and intraoperative guidance from more experienced surgeons, and may represent a highly effective teaching environment. Given that the prevalence of robot-assisted surgery is likely to increase in the future, residency programs will need to adapt to ensure that trainees remain adequately trained in both robotic and traditional procedures.

\section{CASE CONCLUSION}

The patient elects for RALP. The procedure is performed by the urologist without complications and final pathological assessment reveals a well-differentiated, low-grade adenocarcinoma. Followup is arranged with his family physician 6 weeks post-surgery, using PSA levels to monitor for disease recurrence and metastases. PSA $\geq 0.2 \mathrm{ng} / \mathrm{mL}$ with a second confirmatory level is considered positive. Although PSA levels are negligible, the patient reports symptoms of stress incontinence. Kegel exercises and behavioral modifications (eg limiting the intake of fluids such as alcohol and caffeine) are prescribed. Further follow-up visits are arranged every 6 months to continue to monitor PSA levels and assess possible surgical replacement of a sphincter.

Although the surgery was overall successful, there are no substantial benefits of RALP compared to traditional surgery. Moreover, presently, RALP costs more and potentially deprives a resident of a training opportunity. Along with technological advances come challenges that must be addressed, lest these advances prove more detrimental than beneficial. However, advances in surgical technology have been and will continue to be instrumental to improving the quality of patient care.

\section{REFERENCES}

1. Stamey TA, Yang N, Hay AR, et al. Prostate-specific antigen as a serum marker for adenocarcinoma of the prostate. N Engl J Med. 1987;317(15):909-16. https://doi.org/10.1056/NEJM198710083171501

2. Rendon RA, Mason RJ, Marzouk K, et al. Canadian Urological Association recommendations on prostate cancer screening and early diagnosis. Can Urol Assoc J. 2017;11(10):298-309. https://doi. 
org $/ 10.5489 /$ cuaj. 4888

3. Lavallee LT, Binette A, Witiuk K, et al. Reducing the harm of prostate cancer screening: repeated prostate-specific antigen testing. Mayo Clin Proc. 2016;91(1):17-22. https://doi.org/10.1016/j.mayocp.2015.07.030

4. Ankerst DP, Hoefler J, Bock S, et al. Prostate cancer prevention trial risk calculator 2.0 for the prediction of low- vs high-grade prostate cancer. Urology. 2014;83(6):1362-7. https://doi.org/10.1016/j. urology.2014.02.035

5. Roobol MJ, Steyerberg EW, Kranse R, et al. A risk-based strategy improves prostate-specific antigen-driven detection of prostate cancer. Eur Urol. 2010;57(1):79-85. https://doi.org/10.1016/j. eururo.2009.08.025

6. Liss M, Ehdaie B, Loeb S, et al. An update of the American Urological Association white paper on the prevention and treatment of the more common complications related to prostate biopsy. J Urol. 2017;198(2):329-34. https://doi.org/10.1016/j.juro.2017.01.103

7. Raaijmakers R, Kirkels W, Roobol M, et al. Complication rates and risk factors of 5802 transrectal ultrasound-guided sextant biopsies of the prostate within a population-based screening program. Urology. 2002;60(5):826-30.

8. Chiang I, Chang S, Pu Y, et al. Major complications and associated risk factors of transrectal ultrasound guided prostate needle biopsy: a retrospective study of 1875 cases in Taiwan. J Formos Med Assoc. 2007;106(11):929-34. https://doi.org/10.1016/S0929-6646(08)60063-7

9. Vaghefi H, Magi-Galluzzi C, Klein E. Local recurrence of prostate cancer in rectal submucosa after transrectal needle biopsy and radical prostatectomy. Urology. 2005;66(4):881. https://doi.org/10.1016/j. urology.2005.04.005

10. Amin MB, Greene FL, Edge SB, et al. The Eighth Edition AJCC Cancer Staging Manual: Continuing to build a bridge from a population-based to a more "personalized" approach to cancer staging. CA: a cancer journal for clinicians. 2017;67(2):93-9. doi: 10.3322/caac.21388

11. Alberta Health Services. Local prostate cancer [Internet]. Version 2. Alberta Health Services; 2018 Jan [cited 2018 May 8]. Available from: https://www.albertahealthservices.ca/assets/info/hp/cancer/if-hpcancer-guide-gu012-local-prostate.pdf.

12. Chin J, Srigley J, Mayhew L, et al. Guideline for optimization of surgical and pathological quality performance for radical prostatectomy in prostate cancer management: evidentiary base. Can Urol Assoc J. 2013;4(1):13.

13. Sanda M, Cadeddu J, Kirkby E, et al. Clinically localized prostate cancer: AUA/ASTRO/SUO guideline. Part I: risk stratification, shared decision making, and care options. J Urol. 2018;199(3):683-90. https:// doi.org/10.1016/j.juro.2017.11.095

14. Yates DR, Vaessen C, Roupret M. From Leonardo to da Vinci: the history of robot-assisted surgery in urology. Br J Urol Int. 2011;108(11):1708-13. https://doi.org/10.1111/j.1464-410X.2011.10576.x

15. Lanfranco AR, Castellanos AE, Desai JP, et al. Robotic surgery: a current perspective. Ann Surg. 2004;239(1):14-21. https://doi. org/10.1097/01.sla.0000103020.19595.7d

16. Kapoor A. The robotic invasion of Canada. Can Urol Assoc J. 2014;8(56):E466-7. https://doi.org/10.5489/cuaj.2181

17. Tewari A, Sooriakumaran P, Bloch DA, et al. Positive surgical margin and perioperative complication rates of primary surgical treatments for prostate cancer: a systematic review and meta-analysis comparing retropubic, laparoscopic, and robotic prostatectomy. Eur Urol. 2012;62(1):1-15. https://doi.org/10.1016/j.eururo.2012.02.029

18. Finkelstein J, Eckersberger E, Sadri H, et al. Open versus laparoscopic versus robot-assisted laparoscopic prostatectomy: the European and
US experience. Rev Urol. 2010;12(1):35-43.

19. Ficarra V, Novara G, Rosen RC, et al. Systematic review and metaanalysis of studies reporting urinary continence recovery after robotassisted radical prostatectomy. Eur Urol. 2012;62(3):405-17. https://doi. org/10.1016/j.eururo.2012.05.045

20. Ficarra V, Novara G, Ahlering TE, et al. Systematic review and metaanalysis of studies reporting potency rates after robot-assisted radical prostatectomy. Eur Urol. 2012;62(3):418-30. https://doi.org/10.1016/j. eururo.2012.05.046

21. Grant K. How Ontario put the future of operating-room robots in question [Internet]. The Globe and Mail; 2017 Nov 12 [cited 2018 May 8]. Available from: www.theglobeandmail.com/life/health-andfitness/health/the-fight-for-robots-in-canadas-operatingrooms/ article35897282/.

22. Frketich, J. Stunning blow to robotic surgery for prostate cancer in Hamilton [Internet]. The Hamilton Spectator; 2017 Aug 10 [cited 2018 Mar 12]. Available from: https://www.thespec.com/newsstory/7494912-stunning-blow-to-robotic-surgery-for-prostate-cancerin-hamilton/.

23. Ho C, Tsakonas E, Tran K, et al. Robot-Assisted Surgery Compared with Open Surgery and Laparoscopic Surgery: Clinical Effectiveness and Economic Analyses [Internet]. Ottawa: Canadian Agency for Drugs and Technologies in Health; 2011 [cited 2018 Mar 12]. Available from: https://www.cadth.ca/media/pdf/H0496_Surgical_robotics_e. pdf.

24. Beane M. Shadow learning: building robotic surgical skill when approved means fail. Admin Sci Q. 2018 Jan:1-37. https://doi. org/10.1177/0001839217751692

25. Farivar BS, Flannagan M, Leitman IM. General surgery residents' perception of robot-assisted procedures during surgical training. J Surg Ed. 2015 Mar;72(2):235-4.https://doi.org/10.1016/j. jsurg.2014.09.008 